\title{
Critical evaluation of indirect methods for the determination of deoxynivalenol and its conjugated forms in cereals
}

\author{
Alexandra Malachová ${ }^{1,2}$ - Lenka Štočková ${ }^{3}$ - Astrid Wakker ${ }^{4}$. Elisabeth Varga ${ }^{1}$. \\ Rudolf Krska $^{1} \cdot$ Herbert Michlmayr $^{5} \cdot$ Gerhard Adam $^{5} \cdot$ Franz Berthiller $^{1}$
}

Received: 3 April 2015 /Revised: 18 May 2015 / Accepted: 19 May 2015 / Published online: 12 June 2015

(C) The Author(s) 2015. This article is published with open access at Springerlink.com

\begin{abstract}
A critical assessment of three previously published indirect methods based on acidic hydrolysis using superacids for the determination of "free" and "total" deoxynivalenol (DON) was carried out. The modified mycotoxins DON-3glucoside (D3G), 3-acetyl-DON (3ADON), and 15-acetylDON (15ADON) were chosen as model analytes. The initial experiments focused on the stability/degradation of DON under hydrolytic conditions and the ability to release DON from the modified forms. Acidic conditions that were capable of cleaving $\mathrm{D} 3 \mathrm{G}, 3 \mathrm{ADON}$, and $15 \mathrm{ADON}$ to DON were not found, raising doubts over the efficacy of previously published indirect methods for total DON determination. Validation of these indirect methods for wheat, maize, and barley using UHPLC-MS/MS was performed in order to test the accuracy of the generated results. Validation data for DON, D3G, 3ADON, and 15ADON in nonhydrolyzed and hydrolyzed matrices were obtained. Under the tested conditions, DON was not released from $\mathrm{D} 3 \mathrm{G}, 3 \mathrm{ADON}$, or $15 \mathrm{ADON}$ after
\end{abstract}

Alexandra Malachová

alexandra.malachova@boku.ac.at

1 Christian Doppler Laboratory for Mycotoxin Metabolism and Center for Analytical Chemistry, Department of Agrobiotechnology (IFA-Tulln), University of Natural Resources and Life Sciences, Vienna (BOKU), Konrad Lorenz Str. 20, 3430 Tulln, Austria

2 Department of Crop Science, Breeding and Plant Medicine, Faculty of Agronomy, Mendel University in Brno, Zemědělská 1, 61300 Brno, Czech Republic

3 Crop Research Institute, Drnovská 507/73, 16106 Prague 6-Ruzyně, Czech Republic

4 Laboratory of Food Analysis, Department of Bioanalysis, Ghent University, Harelbekestraat 72, 9000 Ghent, Belgium

5 Department of Applied Genetics and Cell Biology, BOKU, Konrad Lorenz Str. 24, 3430 Tulln, Austria hydrolysis and thus none of the published methods were able to cleave the modified forms of DON. In addition to acids, alkaline hydrolysis with $\mathrm{KOH}$ for an extended time and at elevated temperatures was also tested. $3 \mathrm{ADON}$ and $15 \mathrm{ADON}$ were cleaved under the alkaline $\mathrm{pH}$ caused by the addition of $\mathrm{KOH}$ or aqueous $\mathrm{K}_{2} \mathrm{CO}_{3}$ to "neutralize" the acidic sample extracts in the published studies. The published additional DON increase after hydrolysis may have been caused by huge differences in matrix effects and the recovery of DON in nonhydrolyzed and hydrolyzed matrices as well as by the alkaline cleavage of $3 \mathrm{ADON}$ or $15 \mathrm{ADON}$ after the neutralization of hydrolyzed extracts.

Keywords Masked mycotoxins $\cdot$ LC-MS/MS · Chemical hydrolysis $\cdot$ Wheat $\cdot$ Barley $\cdot$ Maize

\section{Introduction}

Deoxynivalenol (DON) is the most frequently occurring mycotoxin worldwide, particularly in cereal crops such as wheat, maize, barley, oats, and rye, and less often in rice, sorghum, and triticale [1]. It belongs to the trichothecenes, a family of closely related compounds produced mainly by Fusarium spp. [1]. F. graminearum and F. culmorum are responsible for Fusarium head blight in wheat (scab) and Fusarium ear rot in maize [2], and are considered to be the most important producers of DON. A direct relationship between the incidence of Fusarium head blight and the contamination of wheat with DON has been established [3].

Plants have a versatile detoxification system that can deal with a wide range of xenobiotics. As DON interacts with vital cell functions of infected plants, it also represents a target for plant defence systems. Basically, detoxification mechanisms involve three major phases, consisting of chemical 
modification (phase I and II metabolism) and compartmentation (phase III metabolism), resulting in the formation of socalled masked mycotoxins [4]. This term was introduced by Gareis et al. [5], and refers exclusively to plant metabolites [4]. Chemical modifications are achieved by linking polar moieties to the parent toxin, leading to a decrease in toxicity towards plants. The modified toxins are partly stored in vacuoles (extractable forms) or irreversibly bound to macromolecules (nonextractable forms) [4]. The major pathway in the biotransformation of DON is conjunction with a glucose moiety, forming deoxynivalenol-3- $\beta$-D-glucoside (D3G) [6]. Ever since an analytical standard of D3G first became commercially available, D3G has been reported as a co-contaminant with DON of cereals and cereal-based products, as reviewed by Berthiller et al. [4]. Moreover, increasing D3G levels have been observed during malting and brewing [7]. In addition, DON-diglucoside and oligoglycosylated DON conjugates with up to four bound hexose units were identified in malt and beer using several sample preconcentration steps prior to analysis performed by liquid chromatography-high-resolution mass spectrometry (LC-HRMS) [8]. Only recently, several other masked forms of DON (DON-S-cysteine, DON-Scysteinyl-glycine, DON-glutathione) have been identified in wheat using an innovative strategy of untargeted screening based on stable isotope labeling followed by LC-HRMS measurements [9].

However, the formation of mycotoxin conjugates is not limited to plant defence mechanisms. For instance, the acetylated forms 3-acetyl-deoxynivalenol (3ADON) and 15-acetyldeoxynivalenol (15ADON) are fungal precursors of DON, although they can also occur as intermediates during DON detoxification in plants [10]. Moreover, mycotoxins can also be modified by bacteria and mammals [4]. Thus, the term "modified mycotoxins" has been introduced to cover all structurally altered forms of mycotoxins, independent of their origin [11]. D3G and ADON can potentially be hydrolyzed to DON during food processing or in the digestive tracts of mammals, and thus contribute to the total dietary exposure to DON [8].

Little is known about the toxicological relevance of modified mycotoxins, but data from the literature show that conjugates of xenobiotics can be toxicologically significant. The Panel on Contaminants in the Food Chain of the European Food Safety Authority decided on a pragmatic approach to human risk assessment by assuming that all modified mycotoxins have the same toxicities as their parent compounds [12]. In line with that, the use of an indirect approach to determine mycotoxins in food and feed seems to be an attractive alternative to target analysis. Indirect methods aim to determine the entire "pool" of modified mycotoxins (extractable and nonextractable forms) in a sample by converting them into the parent toxin using chemical or enzymatic hydrolysis. The main advantages of this approach are that chemical standards of the modified forms are not required and as-yet undetected compounds can also be accounted for. A few indirect methods for the determination of modified forms have also been developed, as reviewed by Berthiller et al. [4]. Three of them deal with DON determination based on chemical hydrolysis (an overview is provided in Fig. 1) [13-15]. Liu et al. published an indirect approach based on trichloroacetic acid (TCA) hydrolysis followed by gas chromatography coupled with electron capture detection (GC-ECD) [13]. Similarly, trifluoroacetic acid (TFA) and trifluoromethanesulfonic acid (TFMSA) hydrolysis were used prior to total DON determination in barley [14] and in maize and wheat [15], respectively. GC-MS as well as GC-MS together with enzyme-linked immunosorbent assay (ELISA) were applied in the latter two studies.

The chemical hydrolysis of carboxylic acid esters is a pHdependent process and is possible under either acidic or alkaline conditions. Acidic hydrolysis of esters involves initial protonation of the carbonyl oxygen. The polarization of the carbonyl group shifts some of the electron density away from the carbon atom, making it more electrophilic and therefore susceptible to the nucleophilic addition of water. Alkaline hydrolysis of esters proceeds via direct nucleophilic addition of the hydroxide ion to the carbonyl group, as it is a stronger nucleophile than water [16]. Glycosidic bonds can also be cleaved chemically. While glycosides are generally susceptible to acidic conditions, in some cases they are susceptible to basic conditions too. This sensitivity to acids is attributed to the sugar moiety, while the nature of the aglycon is more responsible for the instability of glycosides under basic conditions [17].

The aim of the study reported in the present paper was to provide a critical assessment of indirect methods for determining total DON based on acidic hydrolysis. The stability/ degradation of DON, D3G, 3ADON, and 15ADON was tested using spiked samples of wheat, maize, and barley and by employing a liquid chromatographic tandem mass spectrometric (LC-MS/MS) method which was developed and validated for this purpose. The workflow of the experiments performed is also shown in Fig. 1.

\section{Experimental}

\section{Chemicals and reagents}

Methanol, acetonitrile (both LC gradient grade), glacial acetic acid (p.a.), potassium hydroxide (p.a.), and anhydrous sodium bicarbonate were purchased from VWR International $\mathrm{GmbH}$ (Vienna, Austria). Anhydrous potassium carbonate (p.a., $\geq 99 \%$ ) was obtained from Fluka Chemie AG (Buchs, Switzerland). Ammonium acetate (MS grade), trifluoroacetic acid (reagentplus ${ }^{\circledR}, 99 \%$ ), trichloroacetic acid (ACS reagent, 
Previous studies

model analytes
conditions
clean-up
neutralization
analysis

TCA hydrolysis (maize) [13]

DON, 3ADON, 15ADON
$1 \mathrm{M}, 140^{\circ} \mathrm{C}, 40 \mathrm{~min}$
SPE Mycosep ${ }^{\circledR} 227$
$1 \mathrm{M} \mathrm{KOH}$
GC-MS

\section{TFA hydrolysis (barley) [14]}

DON, 3ADON, 15ADON

$1.25 \mathrm{M}, 133^{\circ} \mathrm{C}, 54 \mathrm{~min}$

SPE C18 and alumina

no neutralization

GC-ECD
TFMSA hydrolysis (maize, wheat) [15]

DON, 3ADON, 15ADON

$0.5 \mathrm{M}, 60^{\circ} \mathrm{C}, 20 \mathrm{~min}$ (maize), $40 \mathrm{~min}$ (wheat)

$$
\begin{aligned}
& \text { no clean-up } \\
& 1 \mathrm{M} \mathrm{NaHCO}_{3} \\
& \text { ELISA, GC-MS }
\end{aligned}
$$

\section{Current study}

Hydrolysis of pure standards

DON stability testing

$1 \mu \mathrm{M}-10 \mathrm{mM} \mathrm{KOH}, 0.2-1 \mathrm{M} \mathrm{TCA}$, 0.1-0.5 M TFMSA, $20-130^{\circ} \mathrm{C}, 30-480 \mathrm{~min}$

\section{Hydrolysis of 3ADON and 15ADON}

$0.1 \mathrm{mM} \mathrm{KOH}, 0.1 \mathrm{M}$ TFMSA, $20,37,60^{\circ} \mathrm{C}, 30-480 \mathrm{~min}$

\section{Hydrolysis of D3G}

$0.1 \mathrm{mM} \mathrm{KOH}, 0.1 \mathrm{M}$ and $0.5 \mathrm{M}$ TFMSA, $20,37,60^{\circ} \mathrm{C}, 30-480 \mathrm{~min}$

\section{Hydrolysis of spiked wheat matrix}

Hydrolysis of 3ADON
and 15ADON

$0.1 \mathrm{mM} \mathrm{KOH}, 60^{\circ} \mathrm{C}, 480 \mathrm{~min}$

\section{Hydrolysis of D3G [15]}

$0.5 \mathrm{M}$ TFMSA, $60^{\circ} \mathrm{C}, 480 \mathrm{~min}$

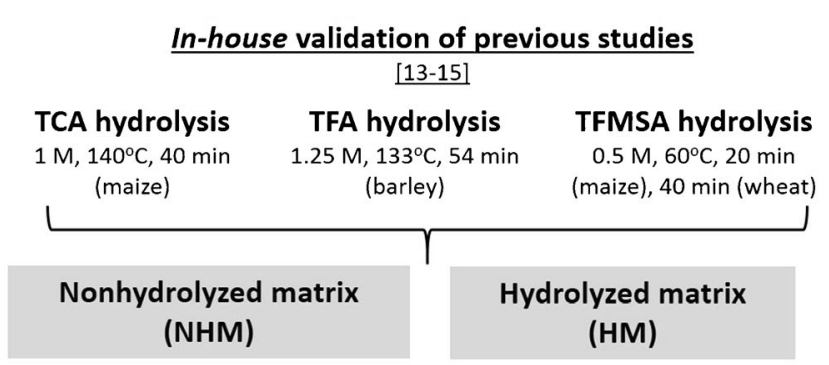

blank cereals spiked with DON, D3G, 3ADON, 15ADON (mixed) at $5 \mathrm{mg} / \mathrm{kg}$

matrix-matched calibration blank cereal matrix hydrolysed and spiked with DON, D3G, 3ADON, 15ADON (individual)

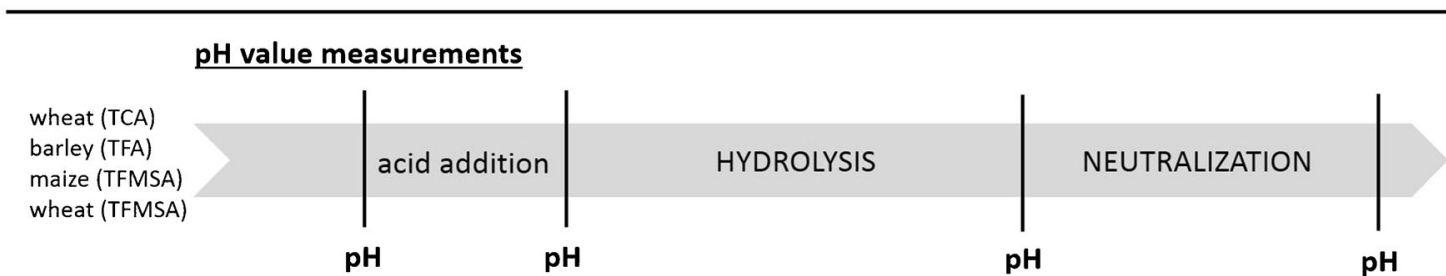

Fig. 1 Overview of three published chemical hydrolysis methods [13-15] for total deoxynivalenol (DON) determination in cereals, and the scheme of the experiments conducted in this study. $3 A D O N 3-$ acetyl-deoxynivalenol, 15ADON 15-acetyl-deoxynivalenol, $D 3 G$ deoxynivalenol-3-glucoside, TCA trichloroacetic acid, TFA trifluoroacetic acid, TFMSA trifluoromethanesulfonic acid $\geq 99 \%$ ), and trifluoromethanesulfonic acid (reagent grade, $98 \%$ ) were obtained from Sigma-Aldrich (Vienna, Austria). Hydrochloric acid (fuming, $37 \%$, p.a.) was purchased from Merck KGaA (Darmstadt, Germany). Water was purified using a Purelab Ultra system (ELGA LabWater, Celle, Germany). Buffer solutions for calibrating the $\mathrm{pH}$ meter, disodium hydrogen phosphate/potassium hydrogen phosphate ( $\mathrm{pH} 7.00$ $\pm 0.01,20^{\circ} \mathrm{C}$ ), boric acid/potassium chloride/sodium hydroxide ( $\mathrm{pH} 10.00 \pm 0.02,20^{\circ} \mathrm{C}$ ), and citric acid/sodium hydroxide/hydrogen chloride ( $\mathrm{pH} 4.00 \pm 0.01,20^{\circ} \mathrm{C}$ ) were purchased from Merck KGaA. Standards for DON, 3ADON, and 15ADON were purchased from Romer Labs GmbH (Tulln, Austria) as stock solutions of $100.8 \mu \mathrm{g} \mathrm{mL}^{-1}, 100.1 \mu \mathrm{g} \mathrm{mL}^{-1}$, and $103.3 \mu \mathrm{g} \mathrm{mL} \mathrm{m}^{-1}$, respectively, in acetonitrile. D3G was initially purified from wheat plants treated with DON at anthesis [18] or prepared by enzymatic synthesis using a purified recombinant UDP-glucosyltransferase (Michlmayr et al., in preparation). A $200 \mu \mathrm{g} \mathrm{mL}^{-1}$ stock solution in methanol was used to prepare the standards. The concentration of D3G was verified with a liquid calibrant of D3G (purity $>95 \%$ ) in acetonitrile obtained from Romer Labs.

\section{Samples}

Ground blank wheat, barley, and maize samples were used as model matrices for the spiking experiments. Wheat and maize were grown by Prof. Marc Lemmens at the Institute for Biotechnology in Plant Production (IFA-Tulln, BOKU, Austria) and a barley sample was kindly provided by Assoc. Prof. Radim Cerkal (Mendel University, Brno, Czech Republic). The artificially inoculated wheat sample of the variety "Sultan" used in this study was provided by the Crop Research Institute (Prague, Czech Republic). 


\section{Hydrolysis experiments with pure standards}

The stability of DON was tested under various hydrolytic conditions. For each of the tested conditions, $35 \mu \mathrm{L}$ of DON stock solution $\left(100.8 \mu \mathrm{g} \mathrm{mL}^{-1}\right)$ were evaporated to dryness under a gentle nitrogen stream in triplicate and the residue was re-dissolved in $7 \mathrm{~mL}$ of the hydrolysis agent. Aqueous solutions of $\mathrm{KOH}(1 \mu \mathrm{M}, 0.1 \mathrm{mM}, 0.1 \mathrm{M})$, TCA $(0.2 \mathrm{M}, 0.5 \mathrm{M}$, $1 \mathrm{M})$, and TFMSA $(0.1 \mathrm{M}, 0.2 \mathrm{M}, 0.5 \mathrm{M})$ were used for 30 , $70,120,240$, and $480 \mathrm{~min}$ at $20^{\circ} \mathrm{C}, 37^{\circ} \mathrm{C}, 60^{\circ} \mathrm{C}, 100^{\circ} \mathrm{C}$, and $130^{\circ} \mathrm{C}$. TFA was not used in these initial experiments because it was not in stock. The following temperatures were maintained: (i) $20^{\circ} \mathrm{C}$ (room temperature), (ii) $37{ }^{\circ} \mathrm{C}$ and $130{ }^{\circ} \mathrm{C}$ using a Kelvitron $\mathrm{T}$ type $\mathrm{T} 6120$ laboratory oven (Heraeus Instruments, Hanau, Germany), and (iii) $60^{\circ} \mathrm{C}$ and $100{ }^{\circ} \mathrm{C}$ using an IKAMAG RET-G laboratory heater (IKA Labortechnik, Staufen, Germany). Afterwards, the hydrolyzed mixtures were neutralized with stoichiometrically equivalent amounts of $\mathrm{HCl}$ or $\mathrm{KOH}$ and measured with UHPLC-MS/ MS. The neutrality of each solution was confirmed by $\mathrm{pH}$ measurements.

The conditions under which DON was found to be stable were used for further hydrolysis experiments with $\mathrm{D} 3 \mathrm{G}$, 3ADON, and 15ADON. Similarly, $1 \mu \mathrm{g}$ of single drieddown standards of $\mathrm{D} 3 \mathrm{G}, 3 \mathrm{ADON}$, and $15 \mathrm{ADON}$ were prepared in triplicate and hydrolyzed with $4 \mathrm{~mL}$ of (i) D3G: $0.1 \mathrm{mM} \mathrm{KOH}, 0.1 \mathrm{M}$ TFMSA, $0.5 \mathrm{M}$ TFMSA at 20, 37, and $60^{\circ} \mathrm{C}$ for $30,70,120,180,240$, and $480 \mathrm{~min}$; (ii) $3 \mathrm{ADON}$ and 15ADON: $0.1 \mathrm{mM} \mathrm{KOH,} 0.1 \mathrm{M}$ TFMSA at 20, 37, and $60^{\circ} \mathrm{C}$ for $30,60,120,180,240,480 \mathrm{~min}$ as well as 16,20 , and $24 \mathrm{~h}$. Neutralization after hydrolysis was performed with appropriate amounts of $\mathrm{HCl}$ or $\mathrm{KOH}$. Again, neutrality was confirmed via $\mathrm{pH}$ measurements. Samples were subsequently measured with UHPLC-MS/MS.

\section{Hydrolysis of conjugated DON in the wheat matrix}

As naturally contaminated wheat samples containing only $15 \mathrm{ADON}$ or $3 \mathrm{ADON}$ (without large amounts of $\mathrm{D} 3 \mathrm{G}$ ) were not available, the experiments were performed with spiked samples. Both a naturally D3G-contaminated sample (containing only small amounts of 3ADON) and a D3G-spiked wheat sample were used.

3ADON, 15ADON: Blank wheat samples $(0.500 \pm$ $0.002 \mathrm{~g}$ ) were weighed into an $8-\mathrm{mL}$ vial and spiked with single standard solutions of $3 \mathrm{ADON}$ or $15 \mathrm{ADON}$ $\left(500 \mu \mathrm{g} \mathrm{kg}^{-1}\right)$ in triplicate. Hydrolysis was performed with $4 \mathrm{~mL}$ of $0.1 \mathrm{mM} \mathrm{KOH}$ at $60{ }^{\circ} \mathrm{C}$ in the laboratory heater for $8 \mathrm{~h}$. The samples were vortexed every $2 \mathrm{~h}$ during hydrolysis. Afterwards, $40 \mu \mathrm{L}$ of $10 \mathrm{mM}$ aqueous $\mathrm{HCl}$ were used for neutralization and the samples were cooled down. For extraction, $4 \mathrm{~mL}$ of acetonitrile were added to the samples in order to get a final extraction composition of acetonitrile:water 1:1, v/v.
The samples were extracted on a GFL 3017 rotary shaker (Burgwedel, Germany) for $30 \mathrm{~min}$. The extracts were transferred to HPLC vials and centrifuged on an Awel MF 48-R centrifuge (Blein, France) at $4500 \mathrm{rpm}(3830 \times \mathrm{g})$ prior to injection. Moreover, further concentrations of $\mathrm{KOH}$ solution were tested. Therefore, $0.500 \pm 0.002 \mathrm{~g}$ of a blank wheat sample were weighed into an $8-\mathrm{mL}$ vial and spiked with $3 \mathrm{ADON}$ and $15 \mathrm{ADON}$, each present at $500 \mu \mathrm{g} \mathrm{kg}^{-1}$, in triplicate. Hydrolysis was performed with $4 \mathrm{~mL}$ of $\mathrm{KOH}$ solution $(2 \mathrm{mM}$, $10 \mathrm{mM}$, or $0.1 \mathrm{M}$ ) at $60^{\circ} \mathrm{C}$ in the laboratory heater for either 240 or $480 \mathrm{~min}$. The subsequent steps were the same as for the hydrolysis with $0.1 \mathrm{mM} \mathrm{KOH}$.

D3G: The hydrolytic method of Tran and Smith [15] was followed with minor modifications. To decrease the cost of analysis, the whole sample preparation procedure was miniaturized (from $5 \mathrm{~g}$ to $0.5 \mathrm{~g}$ of sample), but all the conditions used (i.e., temperature, time of hydrolysis, ratios of sample weight/acid volume/extraction solvent volume/neutralization agent volume) remained the same. Blank wheat samples $(0.500 \pm 0.002 \mathrm{~g})$ were weighed into an 8 - $\mathrm{mL}$ vial and spiked with $500 \mu \mathrm{g} \mathrm{kg}^{-1} \mathrm{D} 3 \mathrm{G}$ in triplicate. Afterwards, $3.6 \mathrm{~mL}$ of deionized water were added and the mixture was shaken on the rotary shaker for $30 \mathrm{~min}$. Hydrolysis was performed with $100 \mu \mathrm{L}$ of $0.5 \mathrm{M}$ TFMSA at $40{ }^{\circ} \mathrm{C}$ for $40 \mathrm{~min}$ in the laboratory heater. The samples were neutralized with $1 \mathrm{M} \mathrm{K}_{2} \mathrm{CO}_{3}$. The final extracts were transferred to HPLC vials and centrifuged at $4500 \mathrm{rpm}(3830 \times \mathrm{g})$ prior to injection. The same protocol was also applied to the naturally contaminated wheat sample containing $3520 \mu \mathrm{g} \mathrm{kg}^{-1} \mathrm{DON}, 460 \mu \mathrm{g} \mathrm{kg}^{-1} \mathrm{D} 3 \mathrm{G}$, and $67 \mu \mathrm{g} \mathrm{kg}^{-1} 3 \mathrm{ADON}$. In order to verify the stability of DON in the matrix under these conditions, another blank sample was spiked with DON at a level of $3500 \mu \mathrm{g} \mathrm{kg}^{-1}$.

\section{In-house method validation}

Sample preparation for the published indirect methods for the determination of DON and the total amount of DON after acidic hydrolysis with trichloroacetic acid [13], trifluoroacetic acid [14], and trifluoromethanesulfonic acid [15] was performed. Again, only $0.5 \mathrm{~g}$ of cereal were used in our case, keeping all other conditions and ratios as specified in the respective publications. Each method was validated for the matrices used in the respective paper, i.e., wheat [13], barley [14], and wheat and maize [15]. In addition, the matrix was validated before hydrolysis (nonhydrolyzed matrix, NHM) and after hydrolysis (hydrolyzed matrix, HM) in order to assure method accuracy.

Two sets of standard stock solutions in acetonitrile were prepared for spiking experiments: (i) individual solutions of DON, D3G, 3ADON, and 15ADON at a concentration of $10 \mu \mathrm{g} \mathrm{mL}{ }^{-1}$ for the $\mathrm{HM}$ validation, and (ii) a mixed solution of all toxins used at level of $10 \mu \mathrm{g} \mathrm{mL}^{-1}$ for the NHM 
validation. In addition, further dilutions were prepared from the $10 \mu \mathrm{g} \mathrm{mL}^{-1}$ mixed solution of all toxins for the preparation of solvent and matrix-matched standards.

Concerning the HM validation, each matrix $(0.500 \pm$ $0.002 \mathrm{~g}$ ) was spiked with single standards of DON, D3G, $3 \mathrm{ADON}$, and $15 \mathrm{ADON}$ at $5 \mu \mathrm{g} \mathrm{kg}^{-1}$ in triplicate and stored at room temperature for $2 \mathrm{~h}$. Afterwards, the following method protocols were used. (i) TCA hydrolysis: $0.5 \mathrm{~g}$ of spiked sample were extracted with $5 \mathrm{~mL}$ of acetonitrile/ water $(84: 16, v / v)$ for $30 \mathrm{~min}$ on a rotary shaker. Afterwards, $2 \mathrm{~mL}$ of deionized water and $1 \mathrm{~mL}$ of $1 \mathrm{M}$ TCA were added. Solvolysis was performed at $140{ }^{\circ} \mathrm{C}$ in the laboratory oven for $40 \mathrm{~min}$. After the mixture had cooled down, $0.5 \mathrm{~mL}$ of $1 \mathrm{M} \mathrm{KOH}$ were added for neutralization and the volume was adjusted to $10 \mathrm{~mL}$ with pure acetonitrile. (ii) TFA hydrolysis: $0.5 \mathrm{~g}$ of the spiked sample were extracted with $4 \mathrm{~mL}$ of acetonitrile/water $(84: 16, v / v)$ for $30 \mathrm{~min}$ on the rotary shaker. Hydrolysis was performed with $100 \mu \mathrm{L}$ of $1.25 \mathrm{M} \mathrm{TFA}$ at $133{ }^{\circ} \mathrm{C}$ in the laboratory oven for $54 \mathrm{~min}$. After cooling down, $125 \mu \mathrm{L}$ of $1 \mathrm{M} \mathrm{KOH}$ were added for neutralization. The extract was mixed and transferred into an HPLC vial. (iii) TFMSA hydrolysis: $0.5 \mathrm{~g}$ of spiked sample were extracted with $3.6 \mathrm{~mL}$ of deionized water and shaken for $30 \mathrm{~min}$ on the rotary shaker. Afterwards, $100 \mu \mathrm{L}$ of $0.5 \mathrm{M}$ TFMSA were added and hydrolyzed for $40 \mathrm{~min}$ (wheat) or $20 \mathrm{~min}$ (maize) at $60{ }^{\circ} \mathrm{C}$ in the lab heater. The whole mixture was adjusted with $1 \mathrm{M}$ sodium bicarbonate to $4 \mathrm{~mL}$.

In addition, the $\mathrm{pH}$ was measured four times in each experiment: before acid addition, directly after acid addition, after hydrolysis, and after the addition of the neutralization agent. The $\mathrm{pH}$ was measured using a $\mathrm{pH}$ electrode on a Microprocessor $\mathrm{pH} 537 \mathrm{pH}$ meter (WTW, Weilheim, Germany), which was calibrated with buffers of $\mathrm{pH} 4$ and 7 (for acidic conditions) or buffers of $\mathrm{pH} 7$ and 10 (for alkaline conditions).

Similarly, the NHM validation was performed using the same protocol as used for the HM validation but with two modifications. Firstly, samples were spiked with the mixed solution of all toxins. Secondly, water was used instead of acid in the protocol described above, and no $\mathrm{KOH}$ was added for neutralization.

Two types of calibration curves covering the concentration range 16.6-750 $\mu \mathrm{g} \mathrm{L}^{-1}$ were prepared. Appropriate amounts of the mixed solution were evaporated under a gentle nitrogen stream and the standards were redissolved in $1 \mathrm{~mL}$ of acetonitrile/water $84: 16, v / v$ for the solvent calibration curve. Similarly, matrix-matched calibrations for NHM and HM were prepared by re-dissolving dried-down standards in 1-mL blank extracts from the respective matrices.

Method performance characteristics were calculated according to the following equations:
Apparent recovery $\left(R_{\mathrm{A}}\right)$ :

$R_{\mathrm{A}}(\%)=\frac{\text { slope }(\text { spiked samples })}{\text { slope }(\text { neat solvent standard })} \times 100$.

Matrix effect as a signal suppression/enhancement (SSE):

SSE $(\%)=\frac{\text { slope }(\text { matrix-matched standard })}{\text { slope }(\text { neat solvent standard })} \times 100$.

Extraction recovery $\left(R_{\mathrm{E}}\right)$ :

$$
R_{\mathrm{E}}(\%)=\frac{R_{\mathrm{A}}}{\mathrm{SSE}} \times 100 .
$$

DON was quantified after the hydrolysis of samples spiked with $\mathrm{D} 3 \mathrm{G}, 3 \mathrm{ADON}$, or $15 \mathrm{ADON}$ using the HM-matched calibration curve. The percentage of DON released was calculated as follows:

$$
\begin{gathered}
\text { DON release }(\%)=\frac{\text { quantified DON level }}{\text { spiked mod.toxin level }} \times \frac{M(\text { mod.toxin })}{M(\text { DON })} \times 100 \\
M=\text { molar mass }\left(\mathrm{g} \mathrm{mol}^{-1}\right) .
\end{gathered}
$$

\section{UHPLC-MS/MS analysis}

A 1290 series UHPLC system (Agilent Technologies, Waldbronn, Germany) coupled to a QTrap $5500 \mathrm{MS} / \mathrm{MS}$ system from AB Sciex (Foster City, CA, USA) was used for analysis. Chromatographic separation was performed on an Acquity UPLC BEH column $(50 \times 2.1 \mathrm{~mm}, 1.7 \mu \mathrm{m}$, Waters, Milford, MA, USA) held at $40{ }^{\circ} \mathrm{C}$. Water/acetic acid $(99: 1, v / v)$ was used as eluent $\mathrm{A}$ and eluent $\mathrm{B}$ consisted of methanol/water/acetic acid 95:4:1, $v / v / v$. Both eluents also contained $5 \mathrm{mM}$ ammonium acetate. Gradient elution started at $10 \% \mathrm{~B}$, which slowly increased to $20 \%$ $\mathrm{B}$ after $2 \mathrm{~min}$, and then increased linearly to $40 \% \mathrm{~B}$ in another 4 min. $90 \% \mathrm{~B}$ was reached by performing a rapid increase for another minute. Re-equilibration for another $2 \mathrm{~min}$ at $10 \% \mathrm{~B}$ was realized prior to further injection. The flow rate was $500 \mu \mathrm{L} \mathrm{min}^{-1}$ and the injection volume was $2 \mu \mathrm{L}$.

The QTrap 5500 was operated in electrospray ionization mode using a TurboV ion spray source with the following settings: curtain gas (CUR), 30 psi (207 kPa, nitrogen); collision gas ( $\mathrm{CAD}$, nitrogen), medium; ion spray voltage, $-4500 \mathrm{~V} /+4500 \mathrm{~V}$; temperature, $550{ }^{\circ} \mathrm{C}$; sheath gas (GS1) and drying gas (GS2), both $80 \mathrm{psi}$ (552 $\mathrm{kPa}$, zero-grade air). Acquisition was performed in the selected reaction monitoring 
mode and the chromatographic run was divided into two individual periods with a settling time of $50 \mathrm{~ms}$. The mass spectrometric conditions for the individual analytes are provided in Table 1.

\section{Results and discussion}

\section{Hydrolysis experiments with pure standards}

The first criterion of an indirect method is that the final product (the compound which is released during the reaction and determined afterwards) has to be stable during the chosen hydrolytic conditions. Therefore, suitable conditions for hydrolysis must be found which leave DON intact. The reagents and conditions of the experiments on the pure standards were based on those used in previous reports [13-15, 19].

When $\mathrm{KOH}$ was used in the hydrolysis of acetylated conjugates of DON, it had no impact on DON stability at concentrations of $1 \mu \mathrm{M}(\mathrm{pH} 8)$ and $0.1 \mathrm{mM}(\mathrm{pH} 10)$ up to $100^{\circ} \mathrm{C}$ for $8 \mathrm{~h}$. Higher concentrations resulted in detectable DON degradation after $1 \mathrm{~h}$. Higher temperatures resulted in even faster degradation. TCA caused fast DON degradation at each tested concentration. The conditions employed by Liu et al. [13], $1 \mathrm{M} \mathrm{TCA}$ at $130{ }^{\circ} \mathrm{C}$, led to DON losses of almost $50 \%$ after $30 \mathrm{~min} .0 .1 \mathrm{M}$ and $0.2 \mathrm{M}$ TFMSA had no impact on the stability of DON at temperatures of up to $60{ }^{\circ} \mathrm{C}$. The conditions used by Tran and Smith [15], $0.5 \mathrm{M}$ TFMSA at $37^{\circ} \mathrm{C}$ for $4 \mathrm{~h}$, seemed to be suitable, as losses of DON did not exceed $5 \%$. However, fast DON degradation was observed at temperatures exceeding $40{ }^{\circ} \mathrm{C}$.

The conditions which passed the first criterion (no impact on DON stability) were used for the hydrolysis of individual standards of D3G, 3ADON, and 15ADON. As expected, D3G was stable at $0.1 \mathrm{mM} \mathrm{KOH}$ at any temperature and duration tested. Using 0.1 M TFMSA for the hydrolysis of D3G was also inefficient. Increasing the concentration of TFMSA to $0.5 \mathrm{M}$ caused the rapid decomposition of $\mathrm{D} 3 \mathrm{G}$ to unknown products at $37^{\circ} \mathrm{C}$ and no release of DON was observed. Slow degradation of $3 \mathrm{ADON}$ was observed when $0.1 \mathrm{M}$ TFMSA was used. The loss reached $11-23 \%$ depending on the temperature applied (the higher the temperature, the greater the loss). In contrast, 0.1 M TFMSA had no effect on 15ADON regardless of the temperature used and time allowed. Hydrolysis of both $3 \mathrm{ADON}$ and $15 \mathrm{ADON}$ to DON was achieved in $1 \mathrm{mM} \mathrm{KOH}$ at $60^{\circ} \mathrm{C}$ for $8 \mathrm{~h}$. The hydrolysis rates for $3 \mathrm{ADON}$ and $15 \mathrm{ADON}$ were 90 and $95 \%$, respectively. There was gradual degradation of the DON formed at longer reaction times. Therefore, the following conditions were used as initial conditions for the subsequent experiments on the wheat matrix: $1 \mathrm{mM} \mathrm{KOH}, 60^{\circ} \mathrm{C}, 8 \mathrm{~h}$.

\section{Alkaline hydrolysis of conjugated DON in the wheat matrix}

Using $1 \mathrm{mM} \mathrm{KOH}$ at $60^{\circ} \mathrm{C}$ for $8 \mathrm{~h}$ to hydrolyze $3 \mathrm{ADON}$ and $15 \mathrm{ADON}$ spiked into wheat did not prove to be successful. On the one hand, $3 \mathrm{ADON}$ and $15 \mathrm{ADON}$ were not completely hydrolyzed to DON, as only $32 \%$ of the spiked 3ADON and $47 \%$ of the spiked $15 \mathrm{ADON}$ were hydrolyzed. On the other, the levels of DON released were lower than expected (less than $25 \%$ ) and did not correspond to the amounts of hydrolyzed $3 \mathrm{ADON}$ and $15 \mathrm{ADON}$. Moreover, it was revealed that the matrix buffers the $\mathrm{pH}$ of the hydrolytic agent from $\mathrm{pH} 10$ to $\mathrm{pH}$ 6. Therefore, the concentration of $\mathrm{KOH}$ was increased and the experiment was repeated. The results are summarized in Table 2. Interestingly, the hydrolysis rates contradict those obtained in the first matrix experiment with
Table 1 Optimized tandem mass spectrometric conditions for deoxynivalenol (DON), DON-3glucoside (D3G), 3-acetyl-DON (3ADON), and 15-acetyl-DON $(15 \mathrm{ADON})$

\begin{tabular}{lllllllll}
\hline Analyte & $\begin{array}{l}\text { Retention } \\
\text { time (min) }\end{array}$ & Period/ion & $\begin{array}{l}\text { Precursor } \\
\text { ion }(\mathrm{m} / \mathrm{z})\end{array}$ & $\begin{array}{l}\text { Product } \\
\text { ions }(\mathrm{m} / \mathrm{z})^{\mathrm{a}}\end{array}$ & $\begin{array}{l}\mathrm{DP} \\
(\mathrm{V})\end{array}$ & $\begin{array}{l}\mathrm{CE} \\
(\mathrm{V})\end{array}$ & $\begin{array}{l}\mathrm{CXP} \\
(\mathrm{V})\end{array}$ & $\begin{array}{l}\text { Dwell } \\
\text { time }(\mathrm{ms})\end{array}$ \\
\hline $\mathrm{DON}$ & 1.20 & $1 /\left[\mathrm{M}+\mathrm{CH}_{3} \mathrm{COO}\right]^{-}$ & 355.1 & 58.9 & -60 & -52 & -7 & 30 \\
& & & & 295.1 & -60 & -14 & -11 & 30 \\
& & & & 265.1 & -60 & -22 & -9 & 30 \\
$\mathrm{D} 3 \mathrm{G}$ & 1.35 & $1 /\left[\mathrm{M}+\mathrm{CH}_{3} \mathrm{COO}\right]^{-}$ & 517.1 & 457.1 & -80 & -18 & -17 & 30 \\
& & & & 427.1 & -80 & -28 & -15 & 30 \\
$3 \mathrm{ADON}$ & 3.33 & $2 /[\mathrm{M}+\mathrm{H}]^{+}$ & 339.1 & 203.0 & 116 & 19 & 8 & 30 \\
& & & & 231.0 & 116 & 17 & 18 & 30 \\
& & & & 213.0 & 116 & 19 & 10 & 30 \\
$15 \mathrm{ADON}$ & 3.45 & $2 /[\mathrm{M}+\mathrm{H}]^{+}$ & 339.1 & 321.0 & 126 & 13 & 14 & 30 \\
& & & & 137.0 & 126 & 15 & 8 & 30 \\
& & & & 261.0 & 126 & 17 & 12 & 30 \\
\hline
\end{tabular}

$D P$ declustering potential, $C E$ collision energy, $C X P$ collision cell exit potential

${ }^{a}$ The first product ion was used as quantifier, the other two transitions served as qualifiers 
Table 2 Release of deoxynivalenol (DON) and residual recoveries of 3-acetylDON (3ADON) and 15-acetylDON (15ADON) after alkaline hydrolysis of a wheat blank sample spiked at $500 \mu \mathrm{g} \mathrm{kg}^{-1}$ with $3 \mathrm{ADON}$ and $15 \mathrm{ADON}$

\begin{tabular}{lllllll}
\hline $\begin{array}{l}\text { Analyte } \\
(\%)\end{array}$ & \multicolumn{6}{l}{ Hydrolytic conditions } \\
\cline { 2 - 6 } & $\begin{array}{l}2 \mathrm{mM} \mathrm{KOH}, \\
60{ }^{\circ} \mathrm{C}, 4 \mathrm{~h}\end{array}$ & $\begin{array}{l}2 \mathrm{mM} \mathrm{KOH}, \\
60{ }^{\circ} \mathrm{C}, 8 \mathrm{~h}\end{array}$ & $\begin{array}{l}10 \mathrm{mM} \mathrm{KOH}, \\
60{ }^{\circ} \mathrm{C}, 4 \mathrm{~h}\end{array}$ & $\begin{array}{l}10 \mathrm{mM} \mathrm{KOH}, \\
60{ }^{\circ} \mathrm{C}, 8 \mathrm{~h}\end{array}$ & $\begin{array}{l}0.1 \mathrm{M} \mathrm{KOH}, \\
60{ }^{\circ} \mathrm{C}, 4 \mathrm{~h}\end{array}$ & $\begin{array}{l}0.1 \mathrm{M} \mathrm{KOH}, \\
60{ }^{\circ} \mathrm{C}, 8 \mathrm{~h}\end{array}$ \\
\hline DON & 43 & 50 & 49 & 52 & 54 & 40 \\
$3 \mathrm{ADON}$ & 91 & 94 & 92 & 88 & 4 & 4 \\
$15 \mathrm{ADON}$ & 97 & 94 & 94 & 93 & 79 & 85 \\
\hline
\end{tabular}

$1 \mathrm{mM} \mathrm{KOH}$. Increasing the concentration of $\mathrm{KOH}$ had only a small impact on the hydrolysis of acetylated DONs. For instance, using $2 \mathrm{mM} \mathrm{KOH}$ at $60{ }^{\circ} \mathrm{C}$ for $8 \mathrm{~h}$ hydrolyzed only $6 \%$ of both $3 \mathrm{ADON}$ and $15 \mathrm{ADON}$. Fast degradation of $3 \mathrm{ADON}$ without further DON release was observed with the highest $\mathrm{KOH}$ concentration tested $(0.1 \mathrm{M})$. Furthermore, the molar sum of $3 \mathrm{ADON}, 15 \mathrm{ADON}$, and DON was higher than the initial sum of these toxins before hydrolysis. This may have been caused either by the presence of additional (unknown) sources of DON in the sample or signal enhancement in LC-MS/MS.

\section{Acidic hydrolysis of D3G in the wheat matrix}

As no suitable conditions for the alkaline hydrolysis of $\mathrm{D} 3 \mathrm{G}$ were found, the method of Tran and Smith using TFMSA [15] was applied to both spiked wheat samples and naturally contaminated wheat. Although D3G disappeared, no DON increase was observed. The reaction seemed to lead to the formation of other products. Interestingly, D3G degradation occurred to a lesser extent in the naturally contaminated sample (55\% of D3G initial levels detected after hydrolysis) compared to the spiked one where only $13 \%$ of D3G were recovered. D3G seems to be better protected by the matrix in naturally contaminated samples. A negative control sample (sample spiked only with DON) was prepared in order to verify the stability of DON. The recovery of DON after hydrolysis was very low, yielding only $31 \%$ of the expected amount. There are three theoretical reasons for this phenomenon: (i) DON is unstable during hydrolysis - which can be excluded based on the results reported above; (ii) low extraction efficiency of DON from the hydrolyzed matrix; or (iii) matrix effects in LC-MS/MS.

\section{In-house method validation}

As we did not find any reports of suitable conditions for acidic or alkaline hydrolyses of either acetylated DONs or D3G, our doubts over the effectiveness of previously published indirect methods for total DON determination [13-15] grew. In order to avoid the generation of biased data due to matrix effects, the developed LC-MS/MS method had to be properly validated. Therefore, sample preparation procedures used in published methods [13-15] were combined with the newly developed LCMS/MS method and validated. The matrix was visibly changed after hydrolysis, so matrix effects must have influenced DON determination in the matrix before and after hydrolysis in different ways. Moreover, it was also suspected that the extraction recovery of DON from NHM was different from the extraction recovery of DON from HM. In order to compare the method accuracy for free (extractable) DON with the accuracy for total DON determination, we decided to validate both matrices (NHM and HM). The performance characteristics of the methods are summarized in Table 3.

Upon comparing the validation data for DON in NHM and HM, huge differences were observed in SSE and $R_{\mathrm{E}}$ values. Strong suppression of the DON signal in TCA-hydrolyzed wheat matrix and TFA-hydrolyzed barley matrix was observed compared to that seen in the respective NHM. In contrast, TFMSA hydrolysis of wheat and maize resulted in high DON signal enhancement when determined by LC-MS/MS. Although other analytical techniques (GC-ECD, GC-MS, and ELISA) were used as analytical tools in the previously published studies, matrix effects should have been taken into account during method development. GC-based methods, just like LC-MS/MS methods, can suffer from matrix effects or other difficulties which hinder accurate determination. It has been stated that GC-based techniques in particular (such as GC-ECD, GC-flame ionization detection, or GC-MS), when used for trichothecene determination, are prone to signal enhancement even when clean-up is performed [20, 21]. Moreover, aside from signal enhancement (the overestimation of a toxin due to matrix effects), other problems such as nonlinearity of calibration curves, poor repeatability, or memory effects from a previous sample injection [20,21] could have led to the overestimation of DON in HM that was observed in the previously published studies [13, 14]. Further, the analytical methods used in these studies were not properly described. There is no information about method linearity and repeatability. More importantly, it is not clear whether the results were calculated using solvent- or matrix-matched calibration curves. In addition, the extraction recovery of DON is higher 
Table 3 Validation data for the indirect approaches to DON determination using UHPLC-MS/MS

\begin{tabular}{|c|c|c|c|c|c|c|c|c|c|c|c|}
\hline \multirow{2}{*}{$\begin{array}{l}\text { Agent } \\
\text { (matrix) }\end{array}$} & \multirow{2}{*}{$\begin{array}{l}\text { Declared increase in DON } \\
\text { after hydrolysis }(\%)\end{array}$} & \multirow[t]{2}{*}{ Analyte } & \multicolumn{4}{|c|}{ Nonhydrolyzed matrix (NHM) } & \multicolumn{4}{|c|}{ Hydrolyzed matrix (HM)* } & \multirow{2}{*}{$\begin{array}{l}\text { DON released } \\
(\%, n=3)\end{array}$} \\
\hline & & & $R_{\mathrm{E}}(\%)$ & $R_{\mathrm{A}}(\%)$ & SSE (\%) & RSD (\%) & $R_{\mathrm{E}}(\%)$ & $R_{\mathrm{A}}(\%)$ & SSE $(\%)$ & RSD (\%) & \\
\hline \multirow{4}{*}{$\begin{array}{l}\text { TCA } \\
\text { (wheat) }\end{array}$} & \multirow[t]{4}{*}{ 13-63 published in [13] } & DON & 59 & 63 & 107 & 5 & 74 & 39 & 53 & 6 & - \\
\hline & & D3G & 82 & 46 & 56 & 1 & 31 & 20 & 65 & 4 & n.d. \\
\hline & & $3 \mathrm{ADON}$ & 62 & 62 & 100 & 2 & 66 & 65 & 98 & 4 & n.d. \\
\hline & & $15 \mathrm{ADON}$ & 60 & 61 & 102 & 3 & 67 & 61 & 91 & 1 & n.d. \\
\hline \multirow{4}{*}{$\begin{array}{l}\text { TFA } \\
\text { (barley) }\end{array}$} & \multirow[t]{4}{*}{ 9-88 published in [14] } & DON & 101 & 97 & 96 & 2 & 120 & 67 & 56 & 21 & - \\
\hline & & D3G & 93 & 62 & 67 & 2 & 83 & 41 & 49 & 2 & n.d. \\
\hline & & $3 \mathrm{ADON}$ & 100 & 100 & 100 & 4 & 119 & 111 & 93 & 1 & n.d. \\
\hline & & $15 \mathrm{ADON}$ & 101 & 94 & 93 & 7 & 92 & 96 & 104 & 3 & n.d. \\
\hline \multirow{4}{*}{$\begin{array}{l}\text { TFMSA } \\
\text { (wheat) }\end{array}$} & \multirow{4}{*}{$\begin{array}{l}7-75 \\
\text { published in [15] }\end{array}$} & DON & 94 & 126 & 134 & 19 & 55 & 82 & 149 & 6 & - \\
\hline & & D3G & 75 & 150 & 200 & 22 & 11 & 12 & 108 & 1 & n.d. \\
\hline & & $3 \mathrm{ADON}$ & 80 & 103 & 128 & 6 & 86 & 45 & 52 & 9 & 33 \\
\hline & & $15 \mathrm{ADON}$ & 82 & 76 & 93 & 6 & 47 & 8 & 17 & 10 & 40 \\
\hline \multirow{4}{*}{$\begin{array}{l}\text { TFMSA } \\
\text { (maize) }\end{array}$} & \multirow{4}{*}{$\begin{array}{l}8-70 \\
\text { published in [15] }\end{array}$} & DON & 103 & 66 & 64 & 4 & 31 & 40 & 128 & 5 & - \\
\hline & & $\mathrm{D} 3 \mathrm{G}$ & 97 & 70 & 72 & 4 & 75 & 54 & 72 & 4 & n.d. \\
\hline & & $3 \mathrm{ADON}$ & 81 & 78 & 96 & 7 & 4 & 2 & 52 & 1 & 31 \\
\hline & & $15 \mathrm{ADON}$ & 91 & 89 & 98 & 5 & 38 & 5 & 13 & 16 & 33 \\
\hline
\end{tabular}

$R_{E}$ extraction recovery, $R_{A}$ apparent recovery, $S S E$ signal suppression or enhancement, $R S D$ relative standard deviation (repeatability, $n=3$, calculated from apparent recovery), $D O N$ deoxynivalenol, $D 3 G$ DON-3-glucoside, 3ADON 3-acetyl-DON, 15ADON 15-acetyl-DON, TCA trichloroacetic acid, TFA trifluoroacetic acid, TFMSA trifluoromethanesulfonic acid, $n . d$. not detected, *except in the TFA hydrolysis procedure, the $\mathrm{pH}$ was not neutral after the addition of alkaline solution to the HM

after TCA and TFA hydrolysis than from NHM. Thus, the final free DON and total DON levels should have been corrected for recovery.

The indirect approach reported by Tran and Smith in 2011 [15] was verified using an AgraQuant ${ }^{\circledR}$ DON assay 0.25/5.0 test kit (Romer Labs Inc., Union, MO, USA). All samples were analyzed for free DON, 3ADON, and 15ADON by GC-MS, but D3G was not taken into account. After hydrolysis, no confirmation of the accuracy of the ELISA results was performed by GC-MS. The authors of this study nevertheless claimed that the increase in DON levels after hydrolysis was caused by the release of this toxin from masked forms other than $3 \mathrm{ADON}$ or $15 \mathrm{ADON}$ that were either present at low levels or below the limit of quantification. It was furthermore argued that $\mathrm{D} 3 \mathrm{G}$ could not have contributed to the "total" DON level because it is unstable under the applied hydrolytic conditions. In gener$\mathrm{al}$, antibody-based methods are considered to be useful tools for screening purposes, but the quantitative results obtained should be verified using a "confirmatory method" [22]. The main risk is of overestimating the results due to antibody cross-reactivity, which was most likely observed by the authors, rather than the release of DON. The results obtained in this study are doubtful for several reasons. First of all, AgraQuant ${ }^{\circledR}$ was found to be a kit that overestimates the DON content compared to LC-MS/ MS results [23-25]. Two comprehensive studies performed on four commercially available DON ELISA kits revealed that DON overestimation is caused by both cross-reactivity with structurally related compounds and by matrix effects. Although the kit manufacturer stated that the cross-reactivity with $3 \mathrm{ADON}$ was $>100 \%$, two studies reported it to be more than $300 \%$ based on the solvent standard [24, 25]. Cross-reactivity with D3G was found to be $113 \%$ in the latter study [25], while Tran and Smith [15] based their calculations on a mere $4.8 \%$, as specified by the manufacturer. Furthermore, a matrix contribution to DON overestimation was reported [24] several years before the published hydrolytic method of Tran and Smith [15]. A certified reference material of wheat was subsequently analyzed by LC-MS/MS, ELISA, and ELISA after MycoSep ${ }^{\text {TM }}$ 226 clean-up [24]. The results obtained using the latter approach corresponded to those determined by LC-MS/MS, while analysis of the raw extract by ELISA resulted in a huge overestimate of the DON in addition to the effect caused by crossreactivity with $3 \mathrm{ADON}, 15 \mathrm{ADON}$, and $\mathrm{D} 3 \mathrm{G}$ [24]. It is likely that the increase in DON levels after hydrolysis, considered to be due to the release of masked forms of this toxin, were actually caused by a combination of matrix effects (cross-reactivity of matrix co-extracts), the huge cross-reactivity of $3 \mathrm{ADON}$, and the cross-reactivity of degraded D3G. In general, it is recommended that matrix-matched calibration curves should be used in ELISA analysis in order to decrease overestimation. It has been proven that every matrix behaves differently in terms of the cross-reactivity caused by matrix co-extracts [24, 25]. Based on our LC-MS/MS validation data, this is also true of nonhydrolyzed and hydrolyzed versions of the same matrix. 
Although the authors' conclusion [15] that D3G is unstable under TFMSA hydrolysis has been confirmed, D3G may still have contributed to the total DON result. The unknown degradation products of $\mathrm{D} 3 \mathrm{G}$ formed during hydrolysis may be cross-reactive to some extent.

Our doubts that none of the published indirect methods work properly were also confirmed by the fact that DON was not detected after TCA and TFA hydrolyses in the samples spiked with pure $3 \mathrm{ADON}, 15 \mathrm{ADON}$, and D3G standards. This means that these compounds - if they were degraded at all—were not cleaved to DON. In addition, the stability of $3 \mathrm{ADON}$ and $15 \mathrm{ADON}$ towards acidic hydrolysis is supported by validation data. There are no differences in $R_{\mathrm{E}}$ and SSE for both acetylated forms of DON when comparing NHM with HM. However, in terms of the validation data for $3 \mathrm{ADON}$ and $15 \mathrm{ADON}$ in TFMSA hydrolysis, unexpectedly low values of $R_{\mathrm{E}}, R_{\mathrm{A}}$, and SSE were obtained in HM (Table 3). Moreover, released DON was detected in $3 \mathrm{ADON}$ - and $15 \mathrm{ADON}$-spiked samples after the hydrolysis procedure. The initial experiments with pure standards revealed that $3 \mathrm{ADON}$ and $15 \mathrm{ADON}$ are fully stable under the acidic conditions used, but they can be cleaved under alkaline conditions. In order to explain those results, the next step was to perform a small-scale hydrolysis experiment and to measure the $\mathrm{pH}$ at each step of the procedure. The results are summarized in Table 4. Thus, in two of the three studies, $3 \mathrm{ADON}$ and $15 \mathrm{ADON}$ were most likely not cleaved during the acidic hydrolysis with TCA or TFMSA, but they were after the addition of an excess of the neutralization agent. The reason that this phenomenon was only observed in the validation data for TFMSA hydrolysis was the order of measurement of the samples. Validation samples of TFMSA hydrolysis were the last in the queue to be measured, $>8 \mathrm{~h}$ after sample preparation ("neutralization"). Also, the matrix-matched standards of $3 \mathrm{ADON}$ and $15 \mathrm{ADON}$ prepared using blank extracts of hydrolyzed and "neutralized" matrices slowly decomposed during analysis due to the alkaline conditions present.

\section{Conclusions}

A critical assessment of three indirect methods for total DON determination based on acidic hydrolysis using TCA [13], TFA [14], or TFMSA [15] was carried out in this study. The first phase of the study focused on the stability/degradation of pure standards of DON, D3G, 3ADON, and 15ADON under various hydrolytic conditions, which was followed by experiments on a wheat matrix. As none of the hydrolytic conditions were found to be suitable for achieving the reliable decomposition of modified forms of DON to the parent toxin (DON), we decided to assess protocols for previously published indirect methods. The most important findings were:

- Validating both the method for "free DON" (NHM) and the method for "total DON" (HM) revealed huge differences in SSE as well as in $R_{\mathrm{E}}$ when DON was determined in NHM and HM. The authors of previous studies [13-15] did not take into account the changes caused to the matrix by hydrolysis. As no information on method performance characteristics and data evaluation or any corrections to the results (in terms of recovery and matrix effects) was provided, the observed DON increase was most likely caused by DON signal enhancement during HM analysis, signal suppression during NHM analysis, or both.

- The exclusion of D3G-the major masked form of DON-as a model toxin in indirect method development in previous studies [13-15] renders these methods unsuitable for routine use.

- An intended neutralization step using aqueous $\mathrm{KOH}$ or $\mathrm{K}_{2} \mathrm{CO}_{3}$ after hydrolysis led to alkalinization of the cereal extracts. Under those conditions, $3 \mathrm{ADON}$ and $15 \mathrm{ADON}$ (and potentially other modified forms) were cleaved to DON and thus further increased the level of DON (or further breakdown products). The increase in DON was not caused by acidic hydrolysis, as claimed by the authors.

In summary, the use of acidic or alkaline hydrolytic procedures for the indirect determination of total DON is strongly discouraged. Indirect methods using enzymatic hydrolysis show more promise. A 1,3- $\beta$-glucanase with high affinity for D3G was identified, but this enzyme was strongly inhibited under the matrix conditions employed here, and sample clean-up was required before enzymatic hydrolysis [26]. Recently, a highly efficient glucosidase from Bifidobacterium that is able to hydrolyze D3G in the matrix was identified [27]. Nevertheless, direct LC-MS/MS utilizing standards for known modified forms presently remains the method of choice to determine the levels of DON and its modified forms in cereals and cereal-based food.
Table $4 \mathrm{pH}$ values obtained during indirect methods for total deoxynivalenol determination

\begin{tabular}{lllll}
\hline Matrix & Before hydrolysis & After acid addition & After hydrolysis & After neutralization \\
\hline Wheat (TCA) & 6.18 & 1.16 & 1.61 & 13.22 \\
Barley (TFA) & 6.24 & 1.70 & 2.16 & 6.93 \\
Wheat (TFMSA) & 5.86 & 3.37 & 3.52 & 10.08 \\
Maize (TFMSA) & 6.11 & 3.15 & 3.97 & 10.07 \\
\hline
\end{tabular}

TCA trichloroacetic acid, TFA trifluoroacetic acid, TFMSA trifluoromethanesulfonic acid 
Acknowledgments The authors would like to thank Prof. Marc Lemmens for kindly providing wheat and maize samples and Prof. Radim Cerkal for providing a barley sample (produced within the project QI111B044 funded by the Ministry of Agriculture of the Czech Republic). Astrid Wakker's stay at IFA-Tulln was realized as part of an ERASMUS+ Bilateral Agreement between Ghent University and BOKU. This work was supported by the Lower Austria Government and the Vienna Science and Technology Fund (WWTF LS12-021) and the Ministry of Agriculture of the Czech Republic (project no. RO0414). The Austrian Federal Ministry of Science, Research and Economy, the Austrian National Foundation for Research, Technology and Development, as well as BIOMIN Holding GmbH and Nestec Ltd. are gratefully acknowledged for funding the Christian Doppler Laboratory for Mycotoxin Metabolism.

Open Access This article is distributed under the terms of the Creative Commons Attribution 4.0 International License (http:// creativecommons.org/licenses/by/4.0/), which permits unrestricted use, distribution, and reproduction in any medium, provided you give appropriate credit to the original author(s) and the source, provide a link to the Creative Commons license, and indicate if changes were made.

\section{References}

1. European Food Safety Authority (EFSA) (2013) Deoxynivalenol in food and feed, occurrence and exposure. EFSA J 11(10):3379. http://www.efsa.europa.eu/en/efsajournal/pub/3379.htm. Accessed 11 Jan 2015

2. Parry DW, Jenkinson P, McLeold L (1995) Fusarium ear blight (scab) in small grain cereals - a review. Plant Pathol 44:207-238

3. Miedaner T, Reinbrecht C, Luaber U, Schollenberger M, Geiger $\mathrm{HH}$ (2001) Effects of genotype and genotype-environment interaction on deoxynivalenol accumulation and resistance to Fusarium head blight in rye, triticale, and wheat. Plant Breed 120:97-105

4. Berthiller F, Crew C, Dall'Asta C, De Saeger S, Haesaert G, Karlovsky P, Oswald IP, Seefelder W, Speijers G, Stroka J (2013) Masked mycotoxins: a review. Mol Nutr Food Res 57:165-189

5. Gareis M, Bauer J, Thiem J, Plank G, Grabley S, Gedek B (1990) Cleavage of zearalenone-glycoside, a "masked" mycotoxin, during digestion in swine. Zentralbl Veterinarmed B 37:236-240

6. Sewald N, Lepschy von Gleissenthall J, Schuster M, Müller G, Aplin RT (1992) Structure elucidation of a plant metabolite of 4desoxynivalenol. Tetrahedron 3:953-960

7. Lancova K, Hajslova J, Poustka J, Krplova A, Zachariasova M, Dostalek P, Sachambula L (2008) Transfer of Fusarium mycotoxins and 'masked' deoxynivalenol (deoxynivalenol-3-glucoside) from field barley through malt to beer. Food Addit Contam A 25:732744

8. Zachariasova M, Vaclavikova M, Lacina O, Vaclavik L, Hajslova J (2012) Deoxynivalenol oligoglycosides: new "masked" Fusarium toxins occurring in malt, beer, and breadstuff. J Agric Food Chem 60:9280-9291

9. Kluger B, Bueschl C, Lemmens M, Berthiller F, Häubl G, Jaunecker G, Adam G, Krska R, Schuhmacher R (2013) Stable isotopic labelling-assisted untargeted metabolic profiling reveals novel conjugates of the mycotoxin deoxynivalenol in wheat. Anal Bioanal Chem 405:5031-5036

10. Boutigny A-L, Richard-Forget F, Barreau C (2008) Natural mechanisms for cereal resistance to the accumulation of Fusarium trichothecenes. Eur J Plant Pathol 121:411-423

11. Rychlik M, Humpf H-U, Marko D, Dänicke S, Mally A, Berthiller F, Klaffke H, Lorenz N (2014) Proposal of a comprehensive definition of modified and other forms of mycotoxins including "masked" mycotoxins. Mycotox Res 30:197-205
12. European Food Safety Authority (EFSA) (2014) Scientific opinion on the risks for human and animal health related to the presence of modified forms of certain mycotoxins in food and feed. EFSA J 12:3916

13. Liu Y, Walker F, Hoeglinger B, Buchenauer H (2005) Solvolysis procedures for the determination of bound residues of the mycotoxin deoxynivalenol in Fusarium species infected grain of two winter wheat cultivars preinfected with barley yellow dwarf virus. J Agric Food Chem 53:6864-6869

14. Zhou B, Li Y, Gillespie J, He G-Q, Horsley R, Schwarz P (2007) Doehlert matrix design for optimization of the determination of bound deoxynivalenol in barley grain with trifluoroacetic acid (TFA). J Agric Food Chem 55:10141-10149

15. Tran ST, Smith TK (2011) Determination of optimal conditions for hydrolysis of conjugated deoxynivalenol in corn and wheat with trifluoromethanesulfonic acid. Anim Feed Sci Technol 163:84-92

16. Larson RA, Weber EJ (1994) Hydrolysis. In: Reaction mechanisms in environmental organic chemistry. CRC, Boca Raton, pp 103-167

17. Brito-Arias M (2007) Hydrolysis of glycosides. In: Synthesis and characterization of glycosides. Springer, New York, pp 304-313

18. Berthiller F, Dall'Asta C, Schuhmacher R, Lemmens M, Adam G, Krska R (2005) Masked mycotoxins: determination of a deoxynivalenol-glucoside in artificially and naturally contaminated wheat by liquid chromatography-tandem mass spectrometry. J Agric Food Chem 53:3421-3425

19. Ehrlich KC, Lillehoj EB (1984) Simple method for isolation of 4deoxynivalenol from rice inoculated with Fusarium graminearum. Appl Environ Microbiol 48:1053-1054

20. Krska R, Baumgartner S, Josephs R (2001) The state-of-the-art in the analysis of type-A and -B trichothecene mycotoxins in cereals. Fresenius J Anal Chem 371:285-299

21. Lattanzio VMT, Pascale M, Visconti A (2009) Current analytical method for trichothecene mycotoxins in cereals. Trends Anal Chem 28:758-768

22. EC (2002) Commission Decision (EC) No. 657/2002 of 12 August 2002 implementing Council Directive 96/23/EC concerning the performance of analytical methods and the interpretation of results. European Community, Brussels. http://eur-lex.europa.eu/ LexUriServ/LexUriServ.do?uri=OJ:L:2002:221:0008:0036:EN:PDF. Accessed 11 Jan 2015

23. Kostelanska M, Hajslova J, Zachariasova M, Malachova A, Kalachova K, Poustka J, Fiala J, Scott PM, Berthiller F, Krska R (2009) Occurrence of deoxynivalenol and its major conjugate, deoxynivalenol-3-glucoside, in beer and some brewing intermediates. J Agric Food Chem 57:3187-3194

24. Zachariasova M, Hajslova J, Kostelanska M, Poustka J, Krplova A, Cuhra P, Hochel I (2008) Deoxynivalenol and its conjugates in beer: a critical assessment of data obtained by enzyme-linked immunosorbent assay and liquid chromatography coupled to tandem mass spectrometry. Anal Chim Acta 625:77-86

25. Dzuman Z, Vaclavikova M, Polisenska I, Veprikova Z, Fenclova M, Zachariasova M, Hajslova J (2014) Enzyme-linked immunosorbent assay in analysis of deoxynivalenol: investigation of the impact of sample matrix on results accuracy. Anal Bioanal Chem 406: 505-514

26. Nielen MWF, Weijers CAGM, Peters J, Weignerová L, Zuilhof H, Franssen MCR (2014) Rapid enzymatic hydrolysis of masked deoxynivalenol and zearalenone prior to liquid chromatography mass spectrometry or immunoassay analysis. World Mycotox J 7: $107-113$

27. Michlmayr H, Varga E, Malachova A, Nguyen N, Lorenz C, Haltrich D, Berthiller F, Adam G (2015) A versatile family 3 glycoside hydrolase from Bifidobacterium adolescentis hydrolyzes $\beta$-glucosides of the Fusarium mycotoxins deoxynivalenol, nivalenol and HT-2 toxin in cereal matrix. Appl Environ Microbiol. doi:10.1128/AEM.01061-15 


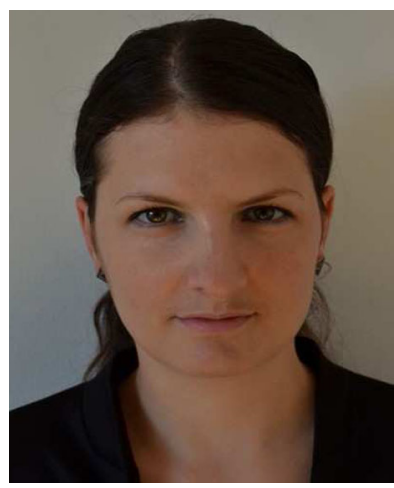

Alexandra Malachová studied analytical chemistry at the Department of Food Analysis and Nutrition, Faculty of Food and Biochemical Technology of the University of Chemistry and Technology (UCT Prague), Czech Republic. She received her $\mathrm{PhD}$ degree in 2012. Currently, she works as a post-doc in the Christian Doppler Laboratory for Mycotoxin Metabolism and the Center for Analytical Chemistry at the Department of Agrobiotechnology (IFA-Tulln) of the University of Natural Resources and Life Sciences, Vienna (BOKU). She is an expert in LC-MS, including high-resolution MS. Her main field of expertise is the development, optimization, and validation of LC-MS-based methods for multiple analytes or methods of analyzing complex matrices.

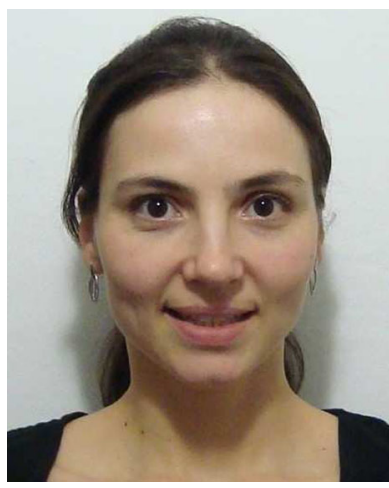

Lenka Štočková works in the Quality of Plant Products Team at the Crop Research Institute in Prague as an analytical chemist. She develops and applies analytical methods for the determination of primary and secondary metabolites in various crop matrices. She is mainly interested in the occurrence of Fusarium mycotoxins and is developing analytical methods for their determination and to elucidate genetic aspects of resistance to Fusarium infection. She also investigates the presence of antioxidants in less well-known crops and changes in antioxidant levels during storage and processing.

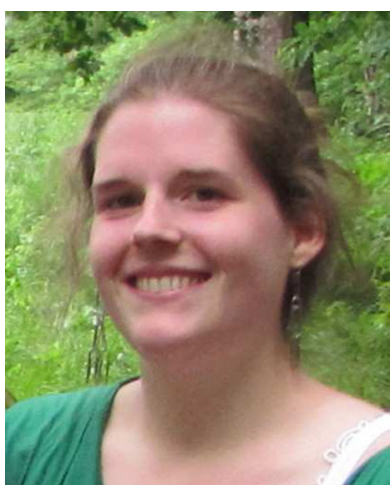

Astrid Wakker studied Pharmaceutical Sciences at Ghent University, Belgium. During her master's thesis at IFA-Tulln, she worked on the development of analytical methods for the detection of conjugated mycotoxins. She is particularly interested in the determination of deoxynivalenol and its conjugated forms in cereals.

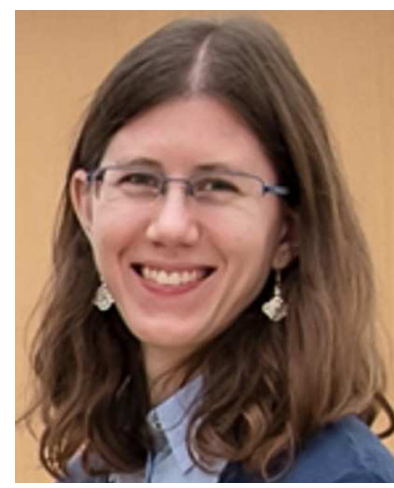

Elisabeth Varga received her $\mathrm{PhD}$ degree from the University of Natural Resources and Life Sciences, Vienna (BOKU) in Austria in 2014 and is currently a postdoctoral fellow in the Christian Doppler Laboratory for Mycotoxin Metabolism and the Center for Analytical Chemistry at the $D$ e $p$ a $t \mathrm{~m}$ e $n t$ Agrobiotechnology (IFA-Tulln) of BOKU. Her research focuses on the development of methods based on liquid chromatography coupled to mass spectrometry for the determination of mycotoxins, their plant metabolites, and other fungal metabolites in food.

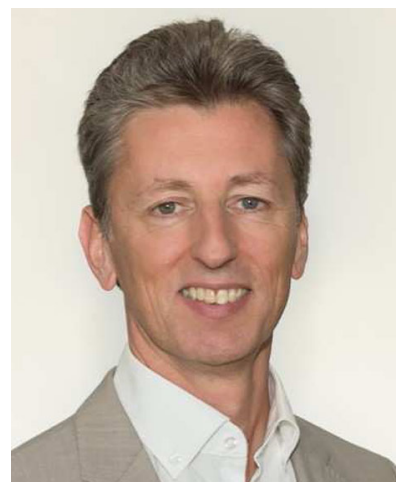

Rudolf Krska is Full Professor for (Bio-)Analytics and Organic Trace Analysis and is Head of the IFA-Tulln (where there are more than 180 co-workers) at the University of Natural Resources and Life Sciences, Vienna (BOKU). In 2009/2010 he worked for 1 year as A/Chief of Health Canada's Food Research Division in Ottawa. He has received 6 scientific awards and is (co-)author of more than $250 \mathrm{SCI}$ publications (h-index: 41). His current research interests are in the areas of plant-fungi metabolomics and novel mass spectrometric methods for the determination of multiple mycotoxins including their conjugation and transformation products in food, feed, and other biological matrices.

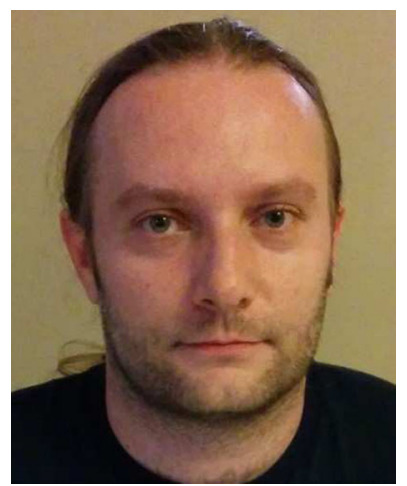

Herbert Michlmayr currently works as a post-doc in the PlantPathogen Interaction Group at the Department of Applied Genetics and Cell Biology, University of Natural Resources and Life Sciences, Vienna (BOKU). He previously worked as a post-doc in the Christian Doppler Research Laboratory of Innovative Bran Biorefinery (CEREVAL) at BOKU, where he carried out research on industrial food and feed applications of wheat bran. He obtained his doctoral degree in 2012 at the Department of Food Science and Technology (BOKU). His key areas of expertise are mycotoxins, protein production and purification, enzyme kinetics, glycosyl hydrolases, glycosyltransferases, and carbohydrate metabolism of lactic acid bacteria. 


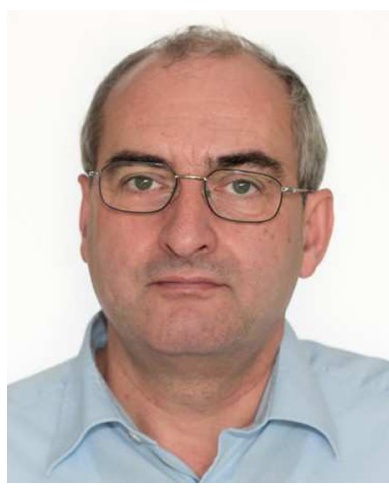

deoxynivalenol-3-O-glucoside.
Gerhard Adam is Leader of the Plant-Pathogen Interaction Group at the Department of Applied Genetics and Cell Biology of the University of Natural Resources and Life Sciences, Vienna (BOKU). His main research interest is plant genes involved in the metabolization of mycotoxins. His group identified the first UDP-glucosyltransferase genes from Arabidopsis and barley that encode UDP-glucosyltransferases with the ability to convert deoxynivalenol into

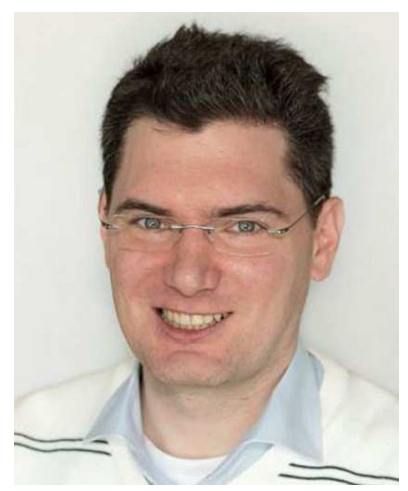

Franz Berthiller is Associate Professor at the University of Natural Resources and Life Sciences, Vienna (BOKU) and Head of the Christian Doppler Laboratory for Mycotoxin Metabolism. In 2006 he received the Brigitte Gedek Award from the German Society of Mycotoxin Research for his $\mathrm{PhD}$ thesis on masked mycotoxins. He continued his research in the lab of Rudi Krska at the IFA-Tulln, and spent some months abroad at the Danish Technical University and the Food Research Division of Health Canada in Ottawa. An expert in the areas of (modified) mycotoxins and LC-MS, his scientific output includes around $100 \mathrm{SCI}$ publications. 